\title{
A Study on the Effects of Breathing Cycle Training Technique Together with Dzikr Recitation towards Achievement of Students' HRV
}

\author{
Muhammad Nubli Abdul Wahab \\ Centre for Modern Language and Human Sciences, \\ University Malaysia Pahang, \\ Lebuhraya Tun Razak, 26300, Gambang \\ Pahang, Malaysia
}

\author{
Azham Abdul Rahman \\ Centre for Modern Language and Human Sciences, \\ University Malaysia Pahang, \\ Lebuhraya Tun Razak, 26300, Gambang
} Pahang, Malaysia

\begin{abstract}
This experiment put emphasis on slow breathing exercise while reciting dzikr. The HRV readings of the students involved were recorded throughout the experiment. Slow breathing or resonant breathing exercises have been proven to be able to lower the heart rate and thus increase the HRV. Recitation of 'dzikr' (Islamic recitation) is known to have positive impacts towards emotion. When properly recited, 'dzikr' could bring calmness to the mind and emotions. An emotion at peace could then bring better results from any actions. Forty secondary school students with behavioral problems were chosen to undergo a biofeedback procedure that incorporated 'dzikr' recitation together with slow breathing technique. 'Dzikr' intervention enabled the students to make changes themselves using the technique of "Heart Rate Variability" (HRV). Students were instructed to perform resonant breathing while chanting slowly and loudly of the "la ilaha illa Allah' 'dzikr'. The study found that students who successfully completed the resonant breathing and 'dzikr' training were able to make changes within themselves. The students had successfully achieved the change score "HRV Coherence" of the VLF spectrum of LF and HF spectrum conditions. The study had found that this technique was very effective and suitable to be implemented to assist students in making behavioral changes. This technique can be used in schools to help improve the students' behavior and thus enabling education programs to be implemented successfully.
\end{abstract}

\section{Keywords}

Slow breathing/resonant breathing, 'dzikr', biofeedback, heart rate variability(HRV).

\section{INTRODUCTION}

\subsection{Dzikr}

Dzikr recitation was an important element in the experiment. The word " $d z i k r$ " is derived from the Arabic word "dzakara" which means remembering.[1] As a terminology, it means practice speech through recitations and remembrance of Allah, The Almighty Creator. Dikr is the best traditions of worship and most pleasing to Allah, the lightest and most easily done by not having certain conditions and rules. It can be done at any time, any place and at any state. [2] Dikr has psychological and spiritual benefits. Psychologically, it gives a sense of spiritual comfort and it gives a sense of being closer to God.[3]

For this research, the zikr methods used were jahri and sirri. Jahri means reciting verbally or aloud by tongue. Sirri or khofi means reciting in an undertone manner or in heart. Dzikr jahri was commonly practiced since the beginning of Islam, especially after prayers.[4] It was also mentioned that $d z i k r$ sirri/khofi is considered as the best of dzikr but dzikr jahri is also allowed.[4] Based on this, despite the difference in $d z i k r$ recitations, both have their own effects on human's physiology as being explained in the next paragraph. The effect of $d z i k r$ recitation was already being proven in a previous experiment. [5]

$D z i k r$, when properly recited could bring calmness to the mind and emotions. An emotion at peace could then bring better results from any actions. The words recited during $d z i k r$ recitation acts as the focal point in treating a person from within. When combined with psychological relaxation within a person, it would positively influence the autonomic nervous system (a control system in the body that acts largely unconsciously) in regulating the heart rate, respiratory rate and the metabolic rate [6], by lowering the physiological processes.

When discussing the practice of $d z i k r$ recitation, the importance of it to the well being of humans as a whole is strongly realized particularly by an Islamic concept known as 'Sufism'. Sufism is a school for the actualization of divine ethics. It involves an enlightened inner being, not intellectual proof; revelation and witnessing, not logic. By divine ethics, it is referring to ethics that transcend mere social convention, a way of being that is the actualization of the attributes of God.[7] Dzikr acts as a way or mediation to connect humans and Allah, The Creator, in order to seek His assistance in life.[8]

The recitation of $d z i k r$ is a religious practice. Through religious practice and religious experience; individuals are able to create positive emotions that have association with mental health. Positive emotions that come from religious practice and experience may buffer the daily hassles and stress. Through rituals and rites of passage, religion can increase the positive psychological outcomes by providing community support during major life changes like marriage and death. The religious community promotes altruism, generosity, and forgiveness attitude that enhance the meanings of an individual life. Through these religious practices and beliefs, communities are strengthened and expanded, providing individuals the access to greater social support while also strengthening familial bonds. Finally, religion creates a framework through which social mores can be understood and followed. In this way, the avoidance of certain behaviors (e.g., criminal behavior, substance abuse) that can lead to negative mental and physical health consequences is encouraged and strengthened in the religious community.[16] 
As being mentioned in the previous paragraph, dzikr has direct effect to human emotions. Dzikr could calm the emotion. A calm and relaxed emotion would then affect the autonomic nervous system that controls the heart beat. It lowers the heart beat and thus increase the HRV. In other words, dzikr affected the HRV by increasing the HRV readings. This statement has already being proven by a previous experiment.[5]

\subsection{Breath cycle}

Breath cycle can be defined as a ventilatory cycle consisting of an inspiration followed by the expiration of a volume of gas called the tidal volume. The duration or total cycle time of a breathing cycle is the breathing or ventilatory period. It is also called respiratory cycle. [9] The respiratory system is involved in the intake and exchange of oxygen and carbon dioxide between an organism and the environment. In airbreathing vertebrates like human beings, respiration takes place in the respiratory organs called lungs. The passage of air into the lungs to supply the body with oxygen is known as inhalation, and the passage of air out of the lungs to expel carbon dioxide is known as exhalation; this process is collectively called breathing or ventilation. In humans and other mammals, the anatomical features of the respiratory system include trachea, bronchi, bronchioles, lungs, and diaphragm. Molecules of oxygen and carbon dioxide are passively exchanged, by diffusion, between the gaseous external environment and the blood. This exchange process occurs in the alveoli air sacs in the lungs.[10]

Inhalation is initiated by the diaphragm and supported by the external intercostal muscles. Normal resting respirations are 10 to 18 breaths per minute, with a time period of 2 seconds. During vigorous inhalation (at rates exceeding 35 breaths per minute), or in approaching respiratory failure, accessory muscles of respiration are recruited for support. These consist of sternocleidomastoid, platysma, and the scalene muscles of the neck. Pectoral muscles and latissimus dorsi are also accessory muscles.Under normal conditions, the diaphragm is the primary driver of inhalation. When the diaphragm contracts, the ribcage expands and the contents of the abdomen are moved downward. This results in a larger thoracic volume and negative pressure (with respect to atmospheric pressure) inside the thorax. As the pressure in the chest falls, air moves into the conducting zone. Here, the air is filtered, warmed, and humidified as it flows to the lungs. During forced inhalation, as when taking a deep breath, the external intercostal muscles and accessory muscles aid in further expanding the thoracic cavity. During inhalation the diaphragm contracts.[10]

Exhalation is generally a passive process; however, active or forced exhalation is achieved by the abdominal and the internal intercostal muscles. During this process air is forced or exhaled out.The lungs have a natural elasticity: as they recoil from the stretch of inhalation, air flows back out until the pressures in the chest and the atmosphere reach equilibrium. During forced exhalation, as when blowing out a candle, expiratory muscles including the abdominal muscles and internal intercostal muscles, generate abdominal and thoracic pressure, which forces air out of the lungs.[10]

The most important element in this experiment was breathing exercises. The subjects in the experiment were intructed to breathe accodingly in order to achieved the required results. Researchers have suggested using breathing therapy for the basic handling of anxiety due to psychophysiological arousal. Researcher reported 75\% success among 1000 patients with anxiety and hyperventilation after using breathing therapy. Breathing is measured by way of lung function parameters such as rate, inhalation, exhalation, pauses, tidal volume, minute volume, flow, $\mathrm{O} 2$ saturation, and end-tidal $\mathrm{CO} 2$. The benefits of breathing therapy, at the same time familiarizing with the habit of slower and deeper breathing, increases mental focus and attention . Deep breathing can be defined as slow diaphragmatic breathing that balances out the oxygen and carbon dioxide levels in the body. The purpose of breathing therapy is to enhance awareness by inducing marked improvement in the perceived quality of the natural rhythm. The benefit of diaphragmatic breathing, it is important that air is inhaled through the nose and exhaled through the mouth and in response to this, the body will react with less severe symptoms in time of high anxiety or panic.[11]

One important aspect of breathing exercises is to make aware of the breathing process. By performing the breathing exercises, a state of slow breath is achieved, hence lowering the heart rate. With controlled respiration, heart rate associated with the lower respiration rate can be reduced and can make the effects of fast heart beat disappear. [11] The respiratory parameters which can affect HRV estimates, include- respiratory frequency (Rf), tidal volume , end tidal partial pressure of carbon di-oxide (PETco2), the time ratio of expiration/inspiration and respiratory dead space.[12] The variation of heart rate in the frequency range of respiration, is known as respiratory sinus arrhythmia (RSA). [12] Respiratory sinus arrhythmia (RSA) is a naturally occurring variation in heart rate that occurs during a breathing cycle. Heart rate increases during inspiration and decreases during expiration. Heart rate is normally controlled by centers in the medulla oblongata. One of these centers, the nucleus ambiguus, increases parasympathetic nervous system input to the heart via the vagus nerve. The vagus nerve decreases heart rate by decreasing the rate of SA node firing. Upon expiration the cells in the nucleus ambiguus are activated and heart rate is slowed down. In contrast, inspiration triggers inhibitory signals to the nucleus ambiguus and consequently the vagus nerve remains unstimulated.[10]

Slow breathing affects the HRV. When doing this slow deep breathing exercises, sympathetic system might have got activated. When the exercise was done regularly for long duration, slowly sympathetic system tone decreased and parasympathetic tone increased.[13] HRV increases as parasympathetic effect increases until it reaches a plateau level. Beyond this level, HRV actually decreases with further increases in parasympathetic effect.[14] Therefore, the slow breathing exercises help to lower the heart rate or increase the HRV for a certain period only.

The following are the steps to be taken to do a slow breathing exercise [15]:

(a)

Step 1

Sit or lie in a comfortable position. Do not try this exercise while standing in case the deep breathing makes you dizzy.

(b)

\section{Step 2}

Put one hand on your abdomen, just below your rib cage, and the other on your chest. Your hands will act as guides so you know you are breathing correctly. 
(c)

Step 3

Inhale as deeply as possible through your nose. You hould feel your stomach expand first, then your chest. Hold this breath for 2 to 5 seconds.

(d)

\section{Step 4}

Exhale through your mouth. You should feel your chest deflate, then your stomach.

(e)

\section{Step 5}

Repeat the breath five times or until your heart rate drops and you feel calm. Check your heart rate with the heart rate monitor, by taking your pulse or by gauging your heartbeat.

\section{METHOD}

The objective of this experiment was to analyze the effects of slow breathing exercise while reciting $d z i k r$ on the biofeedback responses of a group of 40 students. The main biofeedback equipment being used in the experiment was emWave desktop Software Kit devices, to detect their emotion through their heart rate rhythm. The same equipment was also being used in an experiment involving HRV done before.[1]

Slow breathing exercise was emphasized, whereby each student was instructed to execute their breathing accordingly. They were told to inhale deeply for 3 seconds and exhale fully for7 seconds. This particular breathing is called Resonant Breathing. It is slow breathing, (around 3-7 breaths per minute) and relaxed abdominal breathing that can produce a unique state of balance in the autonomic nervous system and resonance or communication between body systems that are connected to breathing.[17]

Before the experiment started, these following items must be made available:

1. Student's demographic form (family background information)

2. Guardian's and student's consent form (permission from parents and student)

3. Student's objective form (student's aspirations)

4. Nijmegen Questionnaire (student's physical health conditions)

The students were divided into two groups, Group A and Group B with 20 students in each group. The members of the groups were determined based on the students' attendance record to school. Group A consisted of students who were absent from class only once or not at all throughout the year. They were students with very few behavioral problems. However, Group B was made up with students who have been absent from school without any valid reasons for more than once. Generally, they were students with multiple behavioral problems. Before the experiment commenced, the information and data about the students must be obtained. The physiological status of the students must be good, so that it would not influence the results. At this stage also, all the relevant forms must be completed. While doing that, the researcher tried to create a friendly environment with the students and tried to make the students felt comfortable.

The next stage was to get the basic HRV readings of the students. These readings would act as a baseline for next experiments. Three minutes was allocated to take the HRV readings of each student. The HRV sensor was attached to the student's ear. After briefly explaining the device to the student, the 'start' button was pressed and the student's HRV reading was taken for three minutes. These readings would act as baseline or reference for the next procedures. After the end of this first session (baseline reading 1), the students should know their actual heart performance at this state based on the readings of the coherent ratios (red, blue and green bars). The following is the script used

"Have a seat and make yourself comfortable."

"This is a biofeedback device. It measures your heart performance"

"If your heart is good, your mind is good too and you would do good things"

"If your heart is bad, the whole body would be bad too"

"Sit quietly, clear your mind, relax"

"The red bar shows that your heart is not good"

(the monitor was shown to the student)

"As a good student, your task is to lower the red bar and raise, make higher the blue and greeen bars"

"You must be able to control your heart so that it stays good"

The next stage of the experiment was $d z i k r$ recitation by jahri or aloud. The students were requested to recite the $d z i k r L a$ ilaha illa Allah aloud. Students were reminded to remember Allah in heart while reciting. They were required to inhale slowly through their nose and while exhaling through their mouth, they recited la ilaha illa Allah. This exercise would proceed for three minutes. The students' HRV readings were taken throughout the exercise. The following is the script used for this procedure:

"Now, I would like you to recite the $d z i k r$ clearly."

"Recite la ilaha illa Allah"

(at this stage, the student recited la ilaha illa Allah)

"Recite it clearly but slowly"

(the student recited the $d z i k r$ again but with slower pace)

"Let the $d z i k r$ enter your heart"

(the student recited the $d z i k r$ with more concentration)

(next, the teacher recited the $d z i k r$ together with the student, giving encouragement)

"Inhale slowly through your nose and exhale through your mouth. While exhaling, recite la ilaha illa Allah"

(after 3 minutes, the recitation of $d z i k r$ was over)

"Now, let us look at your $d z i k r$ perrformance"

(the student's HRV readings before and after $d z i k r$ recitation were shown)

"Is there any difference before and after you recite the $d z i k r$ ?

(the HRV readings were being explained briefly to the student)

"Which one is better, before or after?"

"Dzikr is important to help us change ourselves"

"Now, we continue with our $d z i k r$ "

"Differentiate the red, blue and green score" 
"Congartulations, you have changed now"

The final stage of the experiment was reciting $d z i k r$ in an undertone manner or sirri. Each student was requested to recite the $d z i k r$ in three minutes and their HRV readings were taken throughout the time. They were required to inhale slowly through their nose and while exhaling through their mouth, they recited ilaha illa Allah in their hearts. The following is the script used for this procedure:

"Close your eyes and recite la ilaha illa Allah in your heart."

"Inhale casually, as normal"

"When you exhale, recite the $d z i k r$ in your heart"

(the student exhaled and recited the $d z i k r$ in heart)

"Breathe slower"

"Let the $d z i k r$ enter your heart"

"Do your best"

"Open your eyes and look in front"

"Inhale slowly through your nose and exhale through your mouth. While exhaling,

recite la ilaha illa Allah in your heart"

(after 3 minutes, the recitation of $d z i k r$ was over)

"Now, let us look at your $d z i k r$ perrformance"

(the student's HRV readings before and after $d z i k r$ recitation were shown)
"Is there any difference before and after you recite the $d z i k r$ ?

"Which one is better, before or after? Differentiate the red, blue and green score"

"Congratulations, you have changed now"

"Now, how do you feel?"

\section{RESULTS}

Referring to Table 1 (Group A), it could be observed that the value of VLF spetrum decreased drastically from 61 before $d z i k r$ recitation to 37 after jahri recitation of $d z i k r$. It reached the lowest value of 22 after the recitation of $d z i k r$ by sirri. On the other hand, the opposite pattern could be observed on the values of HF spectrum. The value increased drastically from 19 before $d z i k r$ recitation to 49 after jahri recitattion. The value increased even higher to 63 after the sirri recitation of $d z i k r$.

The results for Group A showed that the students in the group managed to perform the resonant breathing accordingly as being instructed. They had also recited the $d z i k r$ as they were told to do it. Consequently, they managed to achieve the targeted HRV readings, low VLF and high HF. However there was a disruption in the readings of the LF spectrum. It showed a decrease (from 20 to 12) after jahri recitation but then its value increased after the sirri recitation of $z i k r$ (from 12 to 16). According to a previous study[18], this was due to the students' high anxiety level during the pre test or baseline. However, the value increased after the sirri recitation of $d z i k r$. The student's emotion became more stable and calm after the si.rri recitation of $d z i k r$.

Table 1: Mean Values, Standard Deviation of Average Coherence Rate: At Pre and Post For Students In Group A

\begin{tabular}{lcccccc}
\hline & \multicolumn{3}{c}{ Measures } & Mean values & \multicolumn{3}{c}{ Standard deviation } \\
\hline HRV & VLF & LF & HF & VLF & LF & HF \\
Pre & 61 & 20 & 19 & 25 & 12 & 20 \\
Post 1 (jahri) & 37 & 12 & 49 & 34 & 11 & 37 \\
Post 2 (sirri) & 22 & 16 & 63 & 23 & 16 & 36 \\
\hline
\end{tabular}

Referring to Table 2 (Group B), it could be observed that the value of VLF spetrum decreased a bit from 76 before dzikr recitation to 72 after jahri recitation of dzikr. However, the value increased to the highest value of 84 after the recitation of dzikr by sirri. On the other hand, a very different pattern could be observed on the values of HF spectrum. The value increased from 11 before dzikr recitation to 17 after jahri recitattion. In contrast to Table 1 , the value decreased to the lowest value of 6.9 after the sirri recitation of dzikr.
The results for Group B showed that the students in the group failed to perform the resonant breathing accordingly as being instructed. They probably did not recite the dzikr the way they were told to do it. Consequently, they failed to achieve the targeted HRV readings, and achieved highVLF and low HF instead. The value of LF spectrum also decreased consistently, showing that the students failed to calm themselves after experiencing anxiety[18] in the beginning of the procedure.

Table 2: Mean Values, Standard Deviation of Average Coherence Rate: At Pre and Post for Students in Group B

\begin{tabular}{lcccccc}
\hline \multicolumn{1}{c}{ Measures } & \multicolumn{3}{c}{ Mean values } & \multicolumn{3}{c}{ Standard deviation } \\
\hline HRV & VLF & LF & HF & VLF & LF & HF \\
Pre & 76 & 14 & 11 & 20 & 12 & 14 \\
Post 1 (jahri) & 72 & 11 & 17 & 33 & 13 & 33 \\
Post 2 (sirri) & 84 & 9 & 6.9 & 9.8 & 8 & 6.3 \\
\hline
\end{tabular}


The ANOVA statistical test was done on the results for both Group A and Group B students to determine the significant difference against the data . The result was shown in Table 3 below:

Table 3: ANOVA Test for Significant Difference (Group A)

\begin{tabular}{|c|c|c|c|c|c|}
\hline & Groups & Count & Sum & Average & Variance \\
\hline VLF & & 20 & 1312 & 65.6 & 726.8842 \\
\hline LF & Pre-dzikr & 20 & 364 & 18.2 & 180.5895 \\
\hline $\mathrm{HF}$ & & 20 & 324 & 16.2 & 403.5368 \\
\hline VLF & & 20 & 773 & 38.65 & 1083.397 \\
\hline LF & Post-jahri & 20 & 275 & 13.75 & 131.5658 \\
\hline $\mathrm{HF}$ & & 20 & 940 & 47 & 1414.421 \\
\hline VLF & & 20 & 412 & 20.6 & 520.4632 \\
\hline & Post-sirri & 20 & 282 & 14.1 & 229.4632 \\
\hline $\mathrm{HF}$ & & 20 & 1306 & 65.3 & 1228.853 \\
\hline
\end{tabular}

\section{ANOVA}

\begin{tabular}{lcrrrrr}
\hline $\begin{array}{c}\text { Source of } \\
\text { Variation }\end{array}$ & SS & $d f$ & $M S$ & $F$ & P-value & F crit \\
\hline Between Groups & 74322.9 & 8 & 9290.363 & 14.12583 & $1.08 \mathrm{E}-$ & 1.9929 \\
Within Groups & 112464.3 & 171 & 657.686 & & & \\
Total & 186787.2 & 179 & & & & \\
\hline
\end{tabular}

If $\mathrm{F}>\mathrm{F}$ crit, the populations are not equal. In this ANOVA test, as shown in Table 4, F value was 60.84374 and the value of $\mathrm{F}$ crit, was 1.9929. Therefore there was significant difference between the values. The values of VLF, LF and HF before dzikr recitation and after were all significantly different.
There was sufficient evidence to conclude that there was a difference between the value of VLF pre-dzikr and the values of all spectrums post-dzikr. The ANOVA statistical test done showed that there was significant difference between the values concerned, i.e the values at baseline and the values after dzikr recitation, jahri and sirri that was done while performing the resonant breathing.

Table 5: Correlation analysis for Group A

\begin{tabular}{llllllllll}
\hline & VLF & $L F$ & $H F$ & $V L F$ & $L F$ & $H F$ & $V L F$ & $L F$ & $H F$ \\
\hline VLF & 1 & & & & & & & & \\
LF Pre-dzikr & -0.69545 & 1 & & & & & & \\
HF & -0.87688 & 0.264413 & 1 & & & & &
\end{tabular}




$\begin{array}{lllllllllll}\text { VLF } & 0.176574 & -0.38286 & 0.019136 & 1 & & & & & \\ \text { LF Post-jahri } & 0.325069 & -0.19531 & -0.30563 & 0.22183 & 1 & & & & \\ \text { HF } & -0.24209 & 0.364901 & 0.080812 & -0.95527 & -0.49218 & 1 & & & \\ & & & & & & - & & \\ \text { VLF } & 0.413027 & -0.32917 & -0.33413 & 0.52513 & 0.513891 & 0.63355 & 1 & & \\ & & & & & & - & & & \\ \text { LF Post-sirri } & 0.320091 & -0.36052 & -0.18842 & 0.424316 & 0.442405 & 0.50618 & 0.692927 & 1 & \\ & & & & & & & & - & \\ \text { HF } & -0.40711 & 0.370011 & 0.298872 & -0.52511 & -0.52561 & 0.63104 & -0.95023 & 0.88308 & 1\end{array}$

Now, looking at the correlation analysis for Group B, Table 6 , there are several differences if compared to the results in Table 5. The value of VLF before dzikr was directly proportional to: VLF value after jahri dzikr, LF value after jahri dzikr and HF value after sirri dzikr. It means that as the value of VLF before dzikr increased, the other values that were directly proportional to it also increased and vice versa. However, the value of VLF before dzikr was inversely proportional to the value of HF after jahri dzikr, VLF and HF values after sirri dzikr. As the value of VLF pre-dzikr increased, the values that were inversely proportional to it decreased and vice versa.

\section{DISCUSSION}

From the results, it is very clear that breathing exercises is important for HRV change. In this experiment, the students were taught how to perform slow or resonant breathing before their HRV readings were taken. Resonant breathing biofeedback involves slowing the breathing rate to attain resonant frequency, which varies from one individual to another. Breathing at resonant frequency will maximize amplitude of respiratory sinus arrhythmia (RSA) and stimulate the baroreflex. RSA is a component of HRV; it reflectshomeostatic activity and adaptability. RSA refers to cyclical oscillation in heart rate coincident with the respiratory cycle, such that increases in heart rate occur during inhalation and decreases in heart rate during exhalation.[19] The baroreflex or baroreceptor reflex is one of the body's homeostatic mechanisms that helps to maintain blood pressure at nearly constant levels. The baroreflex provides a rapid negative feedback loop in which an elevated blood pressure reflexively causes the heart rate to decrease and also causing blood pressure to decrease. [10] Resonant frequency breathing biofeedback increases baroreflex gain. Breathing at this resonant frequency will reinforce the baroreflexes and thus improve cardiovascular and autonomic stability and, indirectly, reduce emotional instability.[19] As emotion and HRV is closely related[1], HRV readings would certainly be effected as the emotional instability being reduced.

The contribution of dzikr recitation towards the attainment of emotional stability should not be denied. In fact it has been proven by this experiment as well as an experiment done before.[5] With respect to this experiment, the recitation of dzikr is effective when performed during slow breathing. This has been proven in this experiment as well as by the previous experiment.[5] Slow breathing is effective in reducing emotional instability,but the effect is further enhanced by the reciting of dzikr.
Other method of achieving the state of resonant breathing is by the use of a breath pacer. An example of this is E-Z Air, a software program that prompts a person to inhale and exhale at a pre-determined rate. It is downloadable from BFE (The Biofeedback Foundation of Europe) web page, http://www.bfe.org/ez.htm. One of the method to use this software: First, the pacer is set at the number of breaths per minute that is to be tested. It is suggested that it is started at 6 breaths per minute and work way down to 4 BPM in .5 BPM steps. - 6.0, 5.5, 5.0, 4.5, and 4.0. The client/subject is to practice breathing at the selected rate by following the pacer for 2 minutes without recording HRV data. The HRV data will start to be recorded once the client/subject is comfortable breathing at the selected rate. Stop the recording after 2 minutes. Save the data. Let the client/subject rest and breath normally for a few minutes. The pacer is set to the next number of breaths per minute. The client/subject requested to practice breathing at that rate and the process is repeated. This process is to be gone through for each breathing rate. Now HRV data would have been recorded for each breathing rate.[20]

Another matter being observed here was the level of obedience and ability to follow instructions among the students involved. The students would be considered as succesful in terms of this experiment if they managed to achieve the HRV coherence. It was very clear from the results of the experiment that Group A students were successful and Group B failed. Group A succeeded because the members of the group managed to follow closely the instructions given while doing the slow breathing exercise and the dzikr recitation. On the contary, Group B students did not perform either the breathing exercise as being instructed or the dzikr recitation accordingly or even both. It could be concluded also that Group A students were obedient, and Group B the opposite.

\section{CONCLUSION}

The appropriaterly performed slow breathing or resonant breathing exercises are very crucial in order to lower the heart rate and thus improve the HRV coherent score. The recitation of dzikr included in the breathing exercise has further improved the effectiveness towards the HRV change. However, if the instructions to perform the breathing exercises were not closely followed, the results would not be positive, in terms of HRV change. The change in HRV would further result in the change of behaviors. There are other methods known to produce similar effects to HRV, such as yoga. Yoga practice may improve health through breathing exercises, stretching, postures, relaxation, and meditation.[21] Another method is Qigong exercises. Health exercise can 
significantly improve the somatization, interpersonal relationship, depression, anxiety, terror, and psychosis [22]

\section{ACKNOWLEDGMENTS}

This work have been supported under the research grant No. RDU1103101, Universiti Malaysia Pahang, Malaysia.

\section{REFERENCES}

[1] Mohd Rozali Senik and Muhammad Nubli Abdul Wahab, "A pilot study of the effect of zikir on the performance psychology using heart rate variability (hrv)", 4th International Graduate Conference on Engineering, Science \& Huminities (IGCESH ) 2013, 16-17 April (2013)

[2] A.Y. Saleh . Berzikir untuk kesihatan Syaraf, Penerbit Zaman :Jakarta , (2010).

[3] I. Khan. Dimensi Spiritual Psikologi, Pustaka Hidayah;Bandung, (2000)

[4] Al-Bukhari, Shahih al Bukhari page: 109, Chapter I, (810-870 C.E)

[5] Urme Binte Salam, Muhammad Nubli Abdul Wahab, and Ahmad Bin Ibrahim," The Effect Of Zikir on the Performance Psychology of Diploma Student through Heart Rate Variability Biofeedback", Universiti Malaysia Pahang, (2012)

[6] Zaenal Abidin, "Zikir Suatu Tradisi Pesantren Menuju Terapeutik Depresif (KajianMenuju Terapi Psikosomatik dan Neurosis)", Ibda', Vol. 4 No. 1 Jan-Jun (2006)

[7] Nimatullahi Sufi Order, "What is Sufism?", www.nimatullahi.org, (2003)

[8] Ach. Shodiqil Hafil,"Studi Atas Zikir Tarekat Masyarakat Urban Jemaah Tarîqah Qâdirîyahnaqshabandîyah Di Jakarta", Marâji': Islamic Study Journal, Volume 1, Number 1,; ISSN 2406-7636; 36-56 September (2014)

[9] Mosby's Medical Dictionary, 8th edition.

(2009), Elsevier.

[10] Wikipedia, www.wikipedia.org, (2014)

[11] Prima Vitasari, Muhammad Nubli Abdul Wahab, Ahmad Othman and Mohd Ghani Awang, Psychophysiological Treatment In Reduced Anxiety With Biofeedback Training For University Students", International Journal of Technology Management, Volume 1 / (2012) (July-December)
[12] Lt Col KK Tripathi, "Respiration And Heart Rate Variability : A Review With Special Reference To Its Application In Aerospace Medicine", Ind J Aerospace Med 48(1), (2004)

[13] Surekharani Chinagudi, et al.,'Immediate Effect Of Short Duration Of Slow Deepbreathing On Heart Rate Variability In Healthy Adults".National Journal of Physiology, Pharmacy \& Pharmacology | Vol 4 | Issue 3 | $233-235,(2014)$

[14] Jeffrey J. Goldberger, MD; Sridevi Challapalli, MD; Roderick Tung, MD; Michele A. Parker, MS;Alan H. Kadish, MD, "Relationship of Heart Rate Variability to Parasympathetic Effect", Division of Cardiology, Department of Medicine, Northwestern University, Chicago, Ill. () (2001)

[15] American Heart Association, Inc. How To Lower Your Heart Rate Naturally With Breathing Exercises, www.livestrong.com, (2013)

[16] Triantoro Safaria, Ahmad bin Othman and Muhammad Nubli Abdul Wahab, "Religious Coping, Job Insecurity and Job Stress among Javanese Academic Staff: A Moderated Regression Analysis", International Journal of Psychological Studies, Vol. 2, No. 2; December (2010)

[17] Dr Rosalba Courtney Do Phd, "Breath and Body", www.breathandbody.com.au, (2011)

[18] Prima Vitasari, Muhammad Nubli Abdul Wahab, Ahmad Othman, Muhammad Ghani Awang, "The Use of Study Anxiety Intervention in Reducing Anxiety to Improve Academic Performance among University Students", International Journal of Psychological Studies Vol. 2, No. 1; June (2010)

[19] Auditya Purwandini Sutartoa, Muhammad Nubli Abdul Wahab \& Nora Mat Zin, "Resonant Breathing Biofeedback", International Journal of Occupational Safety and Ergonomics (JOSE) (2012), Vol. 18, No. 4, 549-561

[20] Harry Campbell, "The Ideal Breathing Rate is Individual", Biofeedback Resources International, www.biofeedbackinternational com, ( 2008)

[21] Radostina Stoycheva, "Yoga and Heart Rate Variability", www. sweetwaterhrv.com, 2011

[22] British Health Qigong Association, http://healthqigong.org.uk (2015) 